\title{
Reforma política e sanitária: a sustentabilidade do SUS em questão?
}

\section{Health and political reform: is the Brazilian National Health Care System sustainability in question?}

Gastão Wagner deSousa Campos ${ }^{1}$

Abstract This paper presents seven strategies considered to be relevant to ensure the continuity of the Brazilian National Health Care System consolidation and health care reform.

Key words $\mathrm{Health}$ policies, $\mathrm{H}$ ealth care reform and $\mathrm{H}$ ealth care model
Resumo Este artigo apresenta sete estratégias consideradas relevantes para assegurar o prosseguimento da reforma sanitária brasileira e facilitar a consolidação do SU S.

Palavras-chave Política desaúde, Reforma sanitária, M odelo de atenção 
H averia uma interrupção no desenvolvimento do SUS? Talvez não. Há sintomas tanto de crescimento quanto de degradação, portanto, ele ainda se move. No entanto, o devir do SUS nem sempre aponta para seu fortalecimento; há evidências da existência de impasses na sua implantação: financiamento insuficiente; atenção primária crescendo, mas em velocidadee com qualidade abai xo da necessária; regionalização e integração entre municípios e serviços quase virtual; e, ainda, eficácia e eficiência de hospitais e serviços especializados abaixo do esperado 1,2,3.

Mais grave do que tudo isso, contudo, é a impressão de que há um desencantamento com - SUS ou, talvez, um descrédito quanto a nossa (movimento sanitário, políticos, gestores, profissionais, entre outros) capacidade para transformar em realidade uma política tão generosa e racional. Estes sinais de crise, segundo minha modesta opinião e meu imenso desejo, não depõem necessariamente contra as diretrizes centrais do sistema. Isto porque o SU S ainda é uma reforma social incompleta ${ }^{4}$, além do que sua implantação é heterogênea, desigual, conforme características geopolíticas ou geo-culturais decada região5; neste sentido, com certeza, a irregularidade com que vem interferindo de modo positivo sobre a vida cotidiana da maioria do povo tem contribuído para esse desinteresse.

A recuperação de prestígio para o projeto do SUS - se é que algum dia de fato ele o teve depende de uma tríade complexa: primeiro, de criar-se um movimento de peso em defesa de políticas de proteção social e distribuição de renda; segundo, de que alguém consiga apresentálo para a sociedade como uma reforma social significativa e que teria grande impacto sobre 0 bem-estar e proteção social, indicando, com objetividade, os passos e programas necessários; e terceiro, paradoxalmente, sua legitimidade dependemuito deseu desempenho concreto, desua efetiva capacidade para melhorar as condições sanitárias e a saúde das pessoas; nesse caso, a baixa capacidade de gestão, a politicagem, tudo depõe contra o SUS, independente do potencial sanitário contido em suas promessas.

As forças interessadas no avanço do SUS estão, pois, obrigadas a enfrentar estes obstáculos políticos, de gestão e de reorganização do modelo de atenção, cuidando, ao mesmo tempo, de demonstrar a viabilidade da universalidade e da integralidade da atenção à saúde.

Listo algumas alternativas que me parecem meios para garantir esse movimento de mudança:

1- Estimular a constituição de um poderoso e multifacetado movimento social e de opinião em defesa do bem-estar eda instituição de políticas de proteção social no Brasil. A luta pelo sistema de saúde deveria juntar-seà peleja pela distribuição de renda, por políticas de recuperação de moradias e de espaços urbanos degradados, pela educação e segurança públicas. Trazer ao debate a cifra que poderia migrar do setor de serviço da dívida e pagamento de juros para o campo social ${ }^{6}: 50$ bilhões, por exemplo. Dez bilhões, a mais, investidos no SUS somente pelo governo federal, 10 para a educação pública, 10 para programas habitacionais, de saneamento e de recuperação do ambiente, 4 bilhões em programas compensatórios, outros 4 para programas de geração de renda e combate ao desemprego e outras possibilidades, muitas.

Tampouco considerar como um dado estrutural imutável a miséria, a violência urbana; rejeitar e criticar com veemência o mau funcionamento das organizações públicas: recusar a continuidade indefinida da escola que não ensina, do hospital que não cura, da polícia que não aumenta a segurança. Enfim, uma estratégia importante seria articular a defesa do SUS às reformas da ordem social e política brasileira.

Distribuição de renda já e saúde para todos.

2- Se há insuficiência de recursos para o SUS, há também problemas na sua utilização e gerenciamento. Além debuscar-se alternativa para ampliar o financiamento - a principal fonte, sem dúvida, seria diminuir o superávit primário e alterar a política dejuros que interfere no cálculo de parte substancial da dívida - , haveria também que se reformular com rapidez o modelo de repasse de recursos aos estados, municípios e serviços ${ }^{7}$.

Talvez adotar-se um modelo misto: transferência de uma parte dos recursos com base na capacidade instalada, população e encargos sanitários; e outra com base em contratos de gestão elaborados entre os entes federados e que especifiquem metas e compromissos de cada gestor. Esta mesma modalidade de financiamento poderia ser utilizada entre gestor local e prestadores de serviços ${ }^{8}$.

0 contrato de gestão é uma modalidade de relação interinstitucional com grande potencial idade. Primeiro, porque explicita os programas concretos de cada gestor; segundo, introduz em alguma medida uma modalidade real de co-gestão sem diminuir a autonomia e a responsabilidade do encarregado pela execução da atenção à saúde; terceiro, define com clareza a responsabilidade sanitária de cada ente federado; e, ainda, 
institui um sistema regular de avaliação de resultados bastante vinculado à dinâmica da própria gestão.

3- A sustentabilidade política e econômica ea legitimidade sanitária do SU S dependem também de um processo de mudança do modelo de atenção realizado de maneira progressiva, mas que tivesseum grau importante deconcomitância em todo o país. Já existem diretrizes para essa reorganização; em geral, são aquelas originárias da tradição dos sistemas públicos de saúde: funcionamento em rede de serviços com co-responsabilidade e caráter complementar da atenção; importância estratégica da atenção primária, redefinição do papel do hospital e das especialidades (desospitalização); trabalho interdisciplinar eredefinição dos paradigmas tradicionais da medicina e da saúde pública; planejamento segundo necessidades de saúde, eficácia e eficiência e gestão com avaliação de resultados e do desempenho; regi onalização ehierarquização da atenção; integral idade sanitária com atuação clínica epreventiva do sistema; universalidade e saú de como direito. 0 Brasil acrescentou ainda o conceito de sistema descentralizado que combinasse autonomia com o funcionamento em uma redeintegrada; e também o de gestão participativa.

Esta tradição iniciou-se na Europa, ainda durante a primeira metade do século XX, e tem se mantido em vigência apesar da onda neolibe ral tendente a descontruir políticas públicas.

0 modelo deatenção brasileiro passa por um período de transição, em que ainda predominam restos do antigo modo de organizar a atenção, muito semelhanteao norte-americano, centrado em hospitais, especialistas, com pequeno grau de coordenação e de planejamento da assistência e com uma saúde pública restrita à vigilância epidemiológica esanitária. Esta característica éum obstáculo ao desenvolvimento do SUS, uma vez que impõe um padrão de gastos inadequado às necessidades de saúde e ao movimento de reforma do sistema.

4- Dentro dessa linha de mudança de modelos, há uma diretriz que, se adotada, teria grande possibilidade de ampliar a eficiência, eficácia e humanização do Sistema. Trata-se da criação de mecanismos organizacionais, que torne clara e bem estabelecida a responsabilidade sanitária dos entes federados, dos serviços e das equipes de saúde.

Instituir arranjos, que garantam clareza na responsabilização, implicará uma verdadeira re volução cultural euma real alteração dos padrões de gestão contemporânea, balizando com dados concretos o planejamento, os contratos de gestão e 0 acompanhamento permanente de sistemas locais e de serviços de saúde.

Poder-se-ia, para fins analíticos e de gestão, classificar a responsabilidade em macro emicrosanitária.

A responsabilidade macro-sanitária volta-se para a regionalização do Sistema, buscando a definição precisa do quê compete a quem. Para isto, seria fundamental a criação de um organismo em cada região de saúde (à semelhança das Câmaras Bipartites), com poder para estabelecer planos regionais, acompanhando e avaliando a gestão regional. Significa definir que modalidade e que volume de atenção caberia a cada município. Dentro decada cidade, estabelecer do que se encarregará cada serviço hospitalar, de especialidades ou de urgências. Criar responsabilidade macro-sanitária é tornar efetivo e transparenteo encargo sanitário de cada cidade e de cada organização do Sistema. E, com base neste encargo, estabelecer compromissos de co-financiamento entreos entesfederados, bem como possibilitar a gestão do acesso, de maneira que todos os necessitados de cada região tenham acoIhimento equânime.

No caso de excesso de demanda, a adoção de critérios de risco para assegurar acesso a exames complementares ou a outros procedimentos é medida importante e complementar à programação de novos investimentos para correção destas distorções.

Há ainda a responsabilidade micro-sanitária que depende da reorganização do trabalho em saúde, quer na atenção primária, enfermarias, ambulatórios ou centros de especialidades. Esta teria como alvo a inscrição de clientela com uma determinada equipeinterdisciplinar. E também a constituição de sólidos vínculos terapêuticos entreessa equipe de referência epacientes com seus familiares.

Este tipo deorganização precisa atingir todos os serviços do SUS, guardando-se as especificidades de cada organização e de cada local. Caberia a todas estas Equipes de Referência a responsabilidade pela abordagem integral de cada caso em seu nível de competência. Durante o período de tempo em que esteja encarregada do projeto terapêutico de determinada pessoa, deverá mobilizar recursos e rede de apoios necessários para a recuperação e aumento da capacidade de autocuidado (efeito Paidéia) das pessoas e famílias envolvidas.

A alta somente ocorreria quando da transferência da pessoa sob cuidado a outra Equipe, lo- 
calizada na rede básica ou em outra área especializada. 0 tempo de espera não poderia constituir-se em um limbo assistencial. A equipe de referência prosseguiria com o projeto terapêutico durantea espera, inclusive interferindo nos crité rios de acesso. Esta perspectiva reformula o fluxo burocrático e impessoal decorrente dos sistemas tradicionais de referência econtra-referência.

$N$ ão édifícil compreender esta diretriz - a da responsabilidade sanitária -, tampouco é complicado organizar-se arranjos que a façam funcionar no cotidiano (pactos de gestão, contratos com definição de encargos, programas clínicos ou preventivos com caráter vinculatório). 0 difícil é sustentá-la ao longo do tempo, pois estes arranjos alteram as relações de poder entre usuários, profissionais de saúde e gestores.

Em minha opinião, novos recursos financeiros, que visem construir eqüidade, não poderiam ser acordados sem novos contratos que implicassem em redefinição de padrões de responsabilidade macro e micro-sanitária.

A reforma do sistema hospitalar e do atendimento especializado depende centralmente desua reorganização segundo regras de vínculo e em acordo com um sólido processo de contrato de responsabilidades em cada uma das regiões de saúde do Brasil.

0 planejamento e a gestão dos sistemas regionais devem ser coordenados pelas Secretarias de Estado da Saúde com o concurso de municípios, organizados em Conselhos Regionais Bipartites, ou, até mesmo, em conselhos mais amplos que incluam também representação de usuários e de alguns prestadores considerados estratégicos. De qualquer modo, a gestão e o planejamento do SU S regional devem ser realizados em co-gestão, em gestão compartilhada, ainda quea função executiva fique a cargo das secretarias estaduais de saúde. Não se justifica a criação de fundos regionais de saúde sob responsabilidade dos estados, uma vez que o repasse direto ao município com responsabilidade de referência regional é adequado e racional. Tampouco é produtiva a organização regional autônoma dos municípios em consórcios, sem o concurso e coordenação dos estados. Os consórcios devem se submeter aos ditames do órgão colegiado regional.

5- Outro projeto de reforma em andamento, mas com ritmo e resultados ainda insuficientes, éo da estratégia deSaúde da Família. Pelo menos $80 \%$ dos brasileiros necessitariam estar matriculados em equipes de atenção primária. Pela teoria dossistemas de saúde, uma atenção primária que se responsabilize por $80 \%$ dos problemas de saú- de de uma população e que resolva $95 \%$ deles é uma condição fundamental para a viabilidade, inclusivefinanceira, dos sistemas públicos desaúde. Com essa finalidade, a equipes de atenção primária necessitam operar com três funções complementares: a clínica, a de saúde pública e uma de acolhimento (atendimento ao imprevisto e atenção à demanda).

No Brasil, temos valorizado a dimensão de saúde coletiva e subestimado as duas outras. $\mathrm{Na}$ Europa, observa-se tradição distinta, com predomínio da função clínica, o que se reflete na própria composição das equipes, em geral reduzidas a um médico generalista e a alguns técnicos de enfermagem. No Brasil, em função de algumas especificidades de nossa história, influência norte-americana (atenção primária focal e voltada para programas preventivos ou de promoção) quando da definição do conceito de Centro de Saúde e de atenção primária, e em decorrência da importância da doutrina do campo da Saúde Coletiva na constituição do SUS, tendemos a valorizar a função de saúde pública na atenção primária em detrimento da ação clínica. Não seria por outro motivo que nosso programa oficial de atenção primária - 0 Programa de Saúde da Família ${ }^{9}$ - estipula a maior e mais complexa equipe entre todos os sistemas públicos atualmente existentes.

Toda esta confusão epistemológica e doutrinária, mais uma série de inconsistências na política e gestão desse programa, produziram uma lentidão na constituição do Programa de Saúde da Família ou similares no Brasil eisto tem comprometido o SUS como um todo. O financiamento aos municípios é insuficiente - sustentar essa equipe mínima, além de medicamentos e outras despesas, custa bem mais do que os re passes. Os municípios não têm conseguido resolver complexos entraves na gestão de pessoal tendo em vista o apoio tímido de estados e do Ministério da Saúde.

A rede de saúde da família vem sendo criada de maneira desarticulada com o restante do sistema, havendo pouca relação entre atenção primária e especialidades ou hospitais.

Restam ainda outros obstáculos complicados tendo em vista a própria legislação do SUS. Os municípios e estados brasileiros têm autonomia até mesmo para não se comprometem com o SUS, o que gera um contra-senso: a constituição não assegura direito à saúde? U m dos meios para efetivá-lo, segundo a própria lei magna, não passaria pela criação de um sistema com tais e quais características? Como poderia um municí- 
pio ou um estado - quinze anos após a criação do SUS - recusar-se a não cumprir suas diretrizes? Como poderia um município não apresentar um plano e realizar um contrato de gestão se comprometendo a criar tal ou qual rede de atenção à saúde? Isto deveria mudar ou não? Como poderiam os estados e a união não destinarem recursos para os contratos de gestão necessários ao projeto de efetiva constituição do SUS?

Não concebo autonomia sem responsabilidade correspondente; assim, nenhum município, mediante contratos de mútuas obrigações com Estado e União, estaria autorizado a não ter uma política, com metas e prazos bem definidos, de atenção primária e de vigilância em saúde. 0 município que abrigar serviços de referência de abrangência regional, em DST/AIDS, urgência, câncer, entre outros, teria ainda - quinze anos depois da criação do SUS! - autonomia para se recusar a realizar contratos de gestão que assegurassem recursos e atendimento a população da região? M inha resposta é negativa, ainda que na prática a postura de lavar as mãos ainda seja predominante entre os gestores envolvidos com essas questões. Quando as coisas não ocorrem conforme as diretrizes ou os planos, sempre a explicação seria algum fator externo ao ente federal ou estadual em questão.

Este seria outro aspecto da reforma dentro da reforma, um reordenamento necessário, em minha opinião. 0 tempo para adiar a efetiva criação da rede do SU S a cargo de cada município e de cada estado acabou. Quando faltassem recursos, este fato deveria ficar explícito, elaborandose programas para futura execução desses novos projetos segundo sua prioridade.

Outro entrave dentro desse tema estratégico - extensão deuma rede deatenção primária para pelo menos $80 \%$ da população - é a rigidez do programa federal. A lógica do médico e enfermeira generalistas é universal entre sistemas de saúde; no entanto, aqui o Programa de Saúde da Família autoriza somente uma composição de equipe.

H averia que se trabalhar com várias alternativas de composição para as equipes, conforme as características de cada população ou de cada espaço geo-cultural ${ }^{10}$ desde que fossem asseguradas as funções essenciais da rede básica (capacidade de resolver problemas com ações clínicas, de saúde coletiva e mediante o acolhimento).

6 - Outro ponto essencial na reforma da re forma é a revisão do modelo de gestão ainda empregado no SUS, tanto aquele utilizado para administrar os serviços próprios, quanto o vi- gente na relação com prestadores privados ou filantrópicos. Há que se considerar os limites de qualquer reforma gerencial ou do modelo degestão; em geral, o desempenho das organizações depende de um complexo de fatores, entre eles, 0 contexto político, econômico ecultural enão somente de alterações tecno-gerenciais, ainda que estas interfiram no desempenho dos serviços. M esmo assim, é importante complementar-se a Lei Orgânica da Saúde, criando novas modalidades de organização para os serviços próprios do Estado e nova forma de relação entre entes federados e prestadores privados ou filantrópicos.

Acumulam-se evidências sobre a inadequação do modelo atual mente vigente na administração direta para a gestão de hospitais e serviços especializados. A rigidez exigida na execução orçamentária, o emperramento na administração de pessoal, a excessiva interferência político-partidária, tudo isto tem levado grande número de serviços públicos à burocratização e mesmo à degradação organizacional. Ao longo dos anos, gestores inventaram remendos para contornar parte destas dificuldades - ressal tase a criação de autarquias, agências e fundações de apoio com a função de facilitar a gestão financeira e de pessoal. Recentemente, apareceu a alternativa de delegar a gestão destes serviços a entidades civis privadas, criando-se leis e normas que permitiram a existência de Organizações Sociais ${ }^{11}$ ou OSCIP(s) integradas à rede do SUS. Esta última linha de mudança indica uma desistência da administração direta, já que investe em modalidades de gestão com base em contratos entre o gestor - restrito ao papel de regulador - e entes privados sem fim lucrativos. Esta alternativa tem antecedentes no país, uma vez que há anos existem convênios entre 0 SU S e Santas Casas, com problemas que se acumulam tanto em decorrência da insuficiência de financiamento, mas também de problemas gerenciais, ocorrendo também inúmeros casos de degradação organizacional.

Esta discussão sobre o modelo de gestão para - SUS tem sido marcada por posições polares de defesa do status quo da administração pública (estatistas) ou de privatizações em diferentes modalidades (privatistas), com fundamentação bastanteideológica e principista. Há necessidade de se construir proposta com amplo consenso, forte 0 suficiente para romper com a inércia da última década. Seria convenienteinverter-se esta lógica, construindo-se um modelo indutivo; isto é, compor um desenho organizacional a partir de um conjunto de características consideradas 
importantes para o bom desempenho de hospitais e dos centros especializados do SUS. Isto, óbvio, composto com as diretrizes e leis fundantes do sistema: respeitar o fato de que estes serviços fazem parte de um sistema público, hierarquizado e que devem funcionar em rede com outros serviços.

Deste trabalho poderia surgir um desenho do que seriam os Hospitais do SUS. Criar as Organizações do SUS; organizações do SUS sob gestão municipal, estadual ou federal. Este novo desenho para a administração direta deveria resolver alguns dos entraves já identificados decorrentes da atual legislação, que simplesmente estendeu para o SU So modelo de gestão do Estado brasileiro, sem considerar as especificidades do campo da saúde e do SUS em particular.

Assim, estes hospitais e organizações do SUS poderiam incorporar, entre outras, as seguintes características: maior autonomia e integração ao sistema mediante contratos de gestão; financiamento misto (parte fixa e outra variável); conseIho gestor; direção executiva composta mediante critérios técnicos esel eção pública, com mandato enão como cargos de confiança; nova política de pessoal com a possibilidade de alguma modalidade de contratação do tipo emprego público, com carreiras e avaliação de desempenho (remuneração mista); políticas de recrutamento e de educação continuada estaduais e nacional.

Resumindo, esta reforma do modelo de gestão deveria diminuir o peso do governo (poder executivo) na gestão do SUS, com valorização e ampliação dos espaços de gestão compartilhada.
7 - Desenvolvimento científico e incorporação de tecnologia em saúde: Esta éuma área sensível, em queo SU S serelaciona diretamentecom o mercado; no caso, produtores de fármacos e insumos médico-hospitalares, bem como com corporações profissionais. 0 tema dos custos crescentes em saúde, em parte, depende de uma gestão adequada desse fator. 0 M inistério e secretarias de estado da saúde devem consolidar políticas de parceria com universidades einstitutos de pesquisa para desenvolver linhas de pesquisa de interesse público, mas não necessariamente priorizados pela dinâmica de mercado. Além disto, é fundamental que o SUS crie organismos que cumpram com uma função de filtro, criando-se, por exemplo, um Centro de Análise sobre incorporação tecnológica que defina procedimentos a serem ou não protocolados pelo sistema. Os critérios devem ser o de eficácia, eficiência eo dedano provocado, procurando construir uma confiança nacional em seus veredictos, de modo que sirvam de orientação e apoio não somente à gestão do sistema, mas também ao Ministério Público e Poder Judiciário. Setores necessariamente autônomos, mas que poderão apoiar-se em um organismo que demonstreisenção e competência no exercício dessa função de filtro em ciência e tecnologia.

Em síntese: a defesa do SUS e o sucesso do SUS dependem da força com quea sociedade brasileira coloque a vida das pessoas acima de todas as outras racionalidades, eainda compreenda que as políticas públicas podem se constituir em um meio poderoso para a efetiva defesa da vida.

\section{Referências}

1. Oliveira EXG, Travassos C, Carvalho M. Acesso à internação hospitalar em municípios brasileiros em 2000; territórios do SUS. Cad Saúde Pública 2004; 20(2):298-309.

2. Lucchese PTR. Equidade na gestão descentralizada do SUS: desafios para a redução da desigualdade em saúde. Rev C S Col 2003; 8(2):439-448.

3. Vasconcelos CM. Paradoxos da Mudança no SU S [tese de doutorado]. Campinas (SP): Unicamp; 2005.

4. Gerschman S. A democracia inconclusa: um estudo da reforma sanitária brasileira. Rio de Janeiro: Editora da Fiocruz; 1995.

5. Vianna SM, et al. M edindo a desigualdade em saúde no Brasil: uma proposta de monotiramento. Brasília: Organização Pan-Americana da Saúde/Instituto de Pesquisa Aplicada; 2001.

6. Pochmann M. Proteção Social na periferia do capitalismo: considerações sobre o Brasil. São Paulo em Perspectiva 2004; 18(2):3-16.

7. Mendes $R \&$ Mendes $A$. Os Dês(caminhos) do financiamento do SUS. Saúde em Debate 2003; 27(65): 18-25.

8. Porto $S$, et al. Alocação eqüitativa de recursos financeiros: uma alternativa para o caso brasileiro. Saúde em D ebate 2003; 27(65).

9. M inistério da Saúde - Brasil. Saúde da Família: uma estratégia de organização dos serviços de saúde. Brasília, documento oficial da Secretaria de Assistência à Saúde; março/1996.

10. Sutton $M \& M C L$ ean. Determinants or primary medical care quality measured under the UK contract: cross sectional study. BMJ 2006; 332:389-399.

11. Ibañez N. Organizações Sociais de Saúde: o modelo do Estado de São Paulo. Rev C S Col 2001; 6(2): 391-404. 